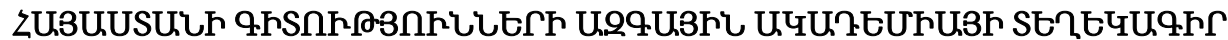 ИЗВЕСТИЯ НАЦИОНАЛЬНОЙ АКАДЕМИИ НАУК АРМЕНИИ
}

\begin{tabular}{lll}
\hline Uthuufuhlum & 68, №2, 2015 & Механика
\end{tabular}

\section{УДК 539.3 \\ ON THE FORMULATION OF THE ELECTRO-ELASTICITY THEORY BOUNDARY VALUE PROBLEMS FOR ELECTRO-MAGNETO-ELASTIC COMPOSITES WITH INTERFACE ROUGHNESS}

Avetisyan A.S.

Fuiuulh punten. Zn

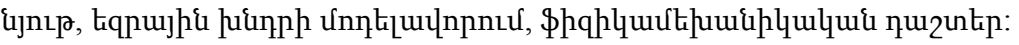

Ключевые слова: контакт сплошных сред, шероховатость поверхности, неоднородный материал, моделирование граничной задачи, физико-механические поля.

Key Words: contact of bodies, interface roughness, inhomogeneous material, modelling of boundary value problems, rough surface, physical and mechanical fields.

U.ltunhujui U.U.

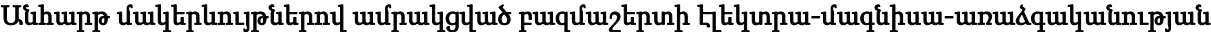
tqnuuph huinph ưuuhi

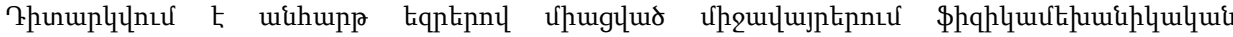

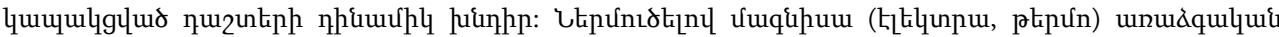

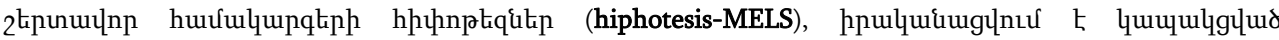

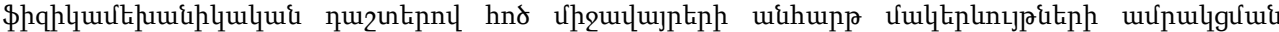

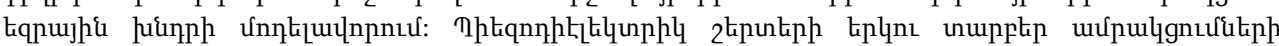

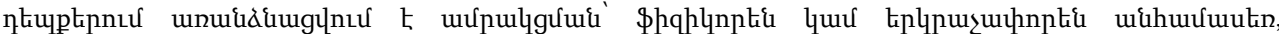

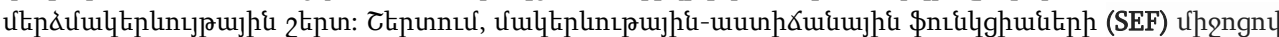

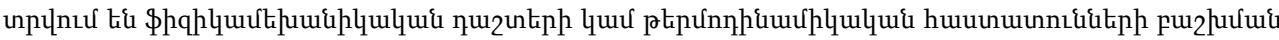

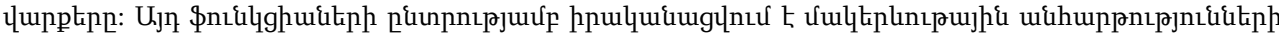

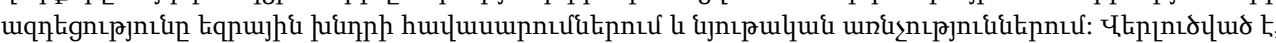

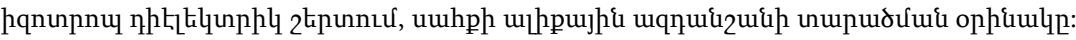

Аветисян А.С.

О постановке краевых задач теории электро-магнито-упругости в трёхслойном композите с учётом шероховатости поверхностей

Рассматривается динамическая задача физико-механических связанных полей в композитах со стыками шероховатых поверхностей. Вводом гипотез магнито- (электро, термо) упругих слоистых систем (гипотезы-MELS) проводится моделирование граничной задачи контакта шероховатых поверхностей сплошных сред со связанными физико-механическими полями. При двух разных моделях соединений толстых пьезодиэлектрических слоёв выделяется приповерхностный геометрически или физически неоднородный слой. В слое задаётся поверхностно-экспоненциальное поведение физико-механических полей или термодинамических постоянных. Выбором поверхностно-экспоненциальной функции (SEF) обеспечивается влияние поверхностной шероховатости в уравнениях и в термодинамических соотношениях задачи. В качестве примера анализируется распространение сдвигового волнового сигнала в изотропном диэлектрике.

he dynamic problem of coupled physical and mechanical fields is considered in composites with joints of rough surfaces. By means of new proposed hypotheses of magnetic- (electro-/thermo-) elastic layered systems (hypotheses-MELS) the boundary problem is modeled for rough interfaces contact of continuous media with interconnected physical and mechanical fields. In various models of joints of thick piezoelectric layers combinations geometrically or physically heterogeneous surface layer is allocated in which the surfaceexponential behavior of physicomechanical fields or thermodynamic constants are given. The effect of surfaces roughness on the equations and the thermodynamic relations is achieved through the choice of surface-exponential functions (SEF). As an example the propagation of the shear wave signal is studied in an isotropic dielectric. 
1. Introduction. Roughness and waviness as residual deformation of the surface layer of the machined surface of deformable element (Fig.1), are the result of uneven edges of the cutting tool, vibration, physical irregularities of the work piece material, etc. and generally violate the material geometric or physical uniformity at the surface zones of the of elements of structure. Quantitatively, the surface roughness is set regardless of the method of surface treatment, but because of the nature of the origin of the residual inhomogeneities and physicomechanical characteristics of the material, the surface of the structural element reacts in different ways to electromechanical or thermo-mechanical loads, which in its turn leads to an additional stress on the surface contrary to a case of perfectly smooth surface of a homogeneous material. In studies of wave processes in structural elements, the fact of the presence of residual surface inconsistencies in the manufacture of this element is often neglected.

Naturally, this approach does not always allow to identify possible surface dynamic phenomena of the wave process, especially in the propagation of the wave signal with amplitude is comparable with size of the actually existing roughness on the surface of the waveguide, or at least does not allow quantitatively to calculate more accurately the characteristics of wave field in the surface area of the waveguide.

In terms of the reliability of research results, it is especially important to investigate propagation of short waves in crystal structures.

The interaction of ultrasound with a rough surface is actively investigated, both from a theoretical and experimental points of view, since the applications of elastic wave phenomena are becoming ever more important in telecommunications (signal processing), medicine (echography), metallurgy (non-destructive testing) and in other fields, too. E.g., millions wave filters, periodic topographic grid and resonators are currently produced each month for mobile phones and computers.

The most important results related to scattering of the waves on the local surface defects, such as grooves, random roughness, elastic wedges are obtained in [1-3], where various theoretical approaches and practical rules for tackling of surface waves problems are given.

Calculation of the effects of roughness and it waviness on the surface of a body does complicates the solution of the mathematical boundary value problem, but makes it possible to identify near-surface effects and more accurately evaluate the quantitative

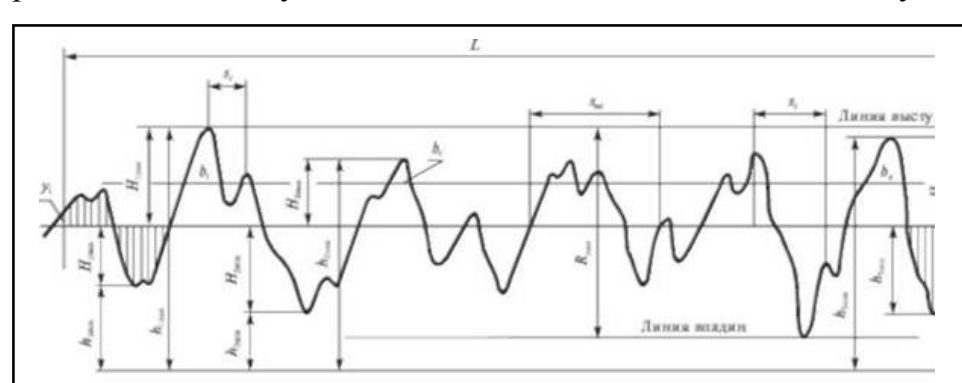

Fig.1. Roughness contour and the basic roughness parameters: $I-$ base line, $m$ - centre line, $S_{i m}$ - the average pitch of the irregularities of the profile, $R_{\max }$ - maximum height of the profile. characteristics of the wave field in the near-surface zone.

In [4] the experimental measurements and calculations of elastic wave propagation and dispersion are reported for a waveguide with randomly rough surfaces, as a model of incipient

corrosion.

Most theoretical studies of acoustic problems in rough surface were studied by means of integral transform methods [5], or by the method of perturbation theory [6].

The propagation of surface acoustic waves across the randomly rough surface of an anisotropic solid is studied in [7]. In a small roughness limit, the dispersion relation for such waves is derived. The frequency dependences of the dispersion 
and attenuation of surface acoustic waves are obtained for the case, when the wavelength is "compared to the transverse correlation length of the roughness. Crystals of cubic, tetragonal, trigonal, hexagonal, and orthorhombic symmetry, adopted in applications, are considered. The effects of piezoelectricity are taken into account through the approach of "partially stiffened elastic constants".

In paper [8] the dispersive effect of roughness is investigated for surface acoustic wave packets (30-200 $\mathrm{MHz}$ frequency range) for different degrees of nanometer roughness on silicon (001 cut) and (111 cut) surfaces. It is shown that the roughness induced frequency dispersion effect is significant, and although available theories agree qualitatively with the results, the theory is not adequate to predict the real surface acoustic wave dispersion.

The problem of a Love wave propagation in a corrugated isotropic layer over a homogeneous isotropic half-space has been investigated in [9] and thee dispersion relation in a corrugated layer medium bounded by irregular boundaries is derived. In special cases, the dispersion relation is reduced for the corrugated layers bounded by periodic boundary surfaces, $d \cdot \cos (p x), d_{1} \cdot \cos (p x)$ and $d_{2} \cdot \cos (p x)$.

In [10] a simple and efficient matrix method is applied to analyze the reflected waves from a layered plate with certain interface features. It is shown that a thin, adhesive layer can be

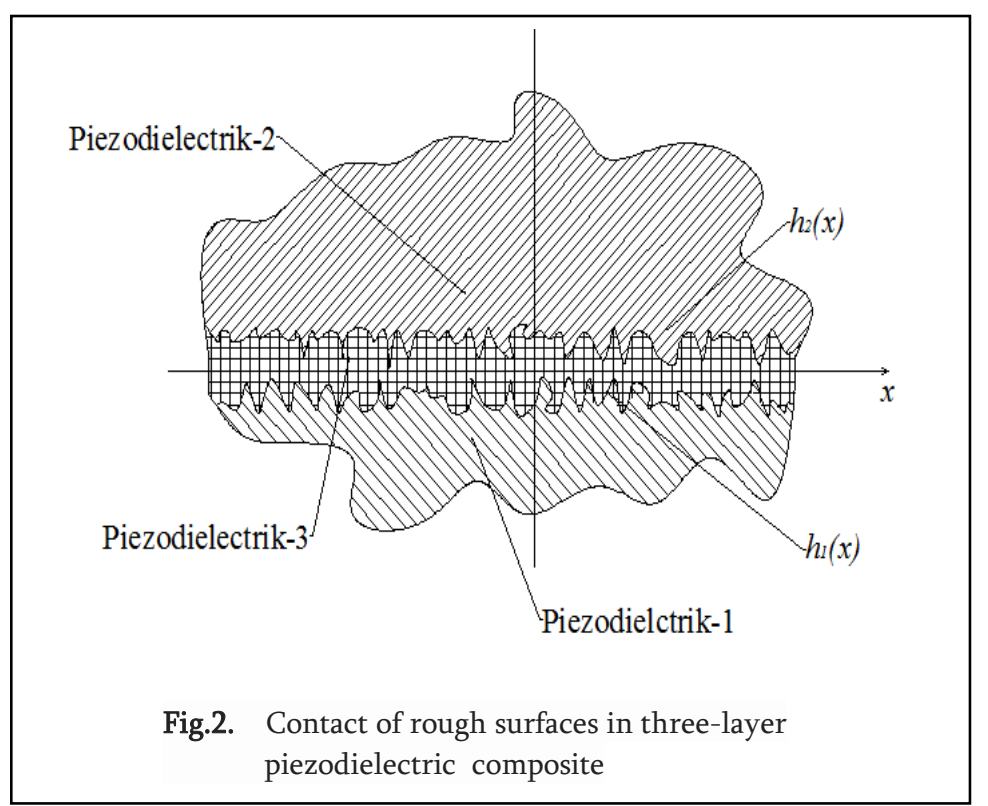

modeled as an equivalent elastic interface with zero thickness

characterized by two adjustable parameters. The paper [11] presents an elastodynamic analysis of twodimensional timeharmonic elastic wave propagation in periodically multilayered elastic composites, which are also frequently referred to as onedimensional phononic crystals, with a periodic

array of strip-like interior or interface cracks. The transfer matrix method and the boundary integral equation method, in conjunction with the Bloch-Floquet theorem are applied to compute the elastic wave fields in layered periodic composites. The effects of the crack size, spacing and location, as well as the incidence angle and the type of incident elastic waves on the wave propagation characteristics in the composite structure are investigated in details. In [12] authors have employed a numerical procedure to analyse the adhesive contact between a soft elastic layer and a rough-rigid substrate. The problem solution belonging to the class of the free boundary problems is obtained by calculating Green's function, which links the pressure distribution to the normal displacements at the interface. The problem is then formulated in the form of a Fredholm integral equation of the first kind with a logarithmic kernel.

When two bodies are separated by a small distance, the roughness starts to play an important role in the interaction between the bodies, their adhesion and friction. Control of this short-distance interaction is crucial for micro and nanoelectromechanical devices, 
microfluidics, and for micro and nanotechnology. In [14] the review of the current state of this problem is considered and an introduction physical origin of the dispersion forces is given. Critical experiments, demonstrating the non-additively of forces and strong influence of roughness on the interaction between bodies are reviewed.

In the theory of magnetoelasticity the hypothesis approach has been often used in [15] for vibration, stability and strength problems of thin-walled plates and shells.

In this paper, by introducing the new hypotheses related to distribution of the elastic displacement and potential of electromagnetic fields in a thin elastic layer of variable thickness of material with magneto-electric properties. The mathematical formulation of the boundary value problem for the three-layer composite electro-magneto-elasticity of piezoelectric crystals is established (Fig. 2).

2. Statement of the problem. Let us consider the propagation of shear plane electro elastic signal $f(x, y, t)=\{0,0, w(x, y), \varphi(x, y), \psi(x, y)\} \exp i(k x-\omega t)$ in the three layer linear electro-magneto-elastic composite described by the following quasi-static equations and linear constitutive relations of electro-magneto-elasticity in each $\mathrm{n}$-th layer.

$$
\begin{aligned}
& \frac{\partial \sigma_{i j}^{(n)}}{\partial x_{j}}=\rho \frac{\partial^{2} u_{i}^{(n)}}{\partial t^{2}}, \frac{\partial D_{i}^{(n)}}{\partial x_{i}}=0, \frac{\partial B_{i}^{(n)}}{\partial x_{i}}=0, \vec{E}^{(n)}=-\operatorname{grad} \varphi^{(n)}, \vec{B}^{(n)}=-\operatorname{grad} \psi^{(n)} \\
& \sigma_{i j}^{(n)}=c_{i j p q}^{(n)}\left(\frac{\partial u_{p}^{(n)}}{\partial x_{q}}+\frac{\partial u_{q}^{(n)}}{\partial x_{p}}\right)+e_{m i j}^{(n)} \frac{\partial \varphi^{(n)}}{\partial x_{m}}+d_{m i j}^{(n)} \frac{\partial \psi^{(n)}}{\partial x_{m}}-\text { mechanical stresses, } \\
& D_{j}^{(n)}=e_{p q j}^{(n)}\left(\frac{\partial u_{p}^{(n)}}{\partial x_{q}}+\frac{\partial u_{q}^{(n)}}{\partial x_{p}}\right)-\varepsilon_{i j}^{(n)} \frac{\partial \varphi^{(n)}}{\partial x_{i}}-g_{m j}^{(n)} \frac{\partial \psi^{(n)}}{\partial x_{m}}-\text { electrical displacements, } \\
& B_{j}^{(n)}=d_{p q j}^{(n)}\left(\frac{\partial u_{p}^{(n)}}{\partial x_{q}}+\frac{\partial u_{q}^{(n)}}{\partial x_{p}}\right)-g_{i j}^{(n)} \frac{\partial \varphi^{(n)}}{\partial x_{i}}-\mu_{m j}^{(n)} \frac{\partial \psi^{(n)}}{\partial x_{m}}-\text { magnetic inductions. }
\end{aligned}
$$

As it is known [16 ], electro-magneto elasticity problems, as well as problems of the plane and anti-plane deformations decouple not for all symmetries of crystal depending both of mixed boundary conditions and the structure of the matrix of physical and mechanical constant $c_{i j p q}^{(n)}, e_{i p q}^{(n)}, \varepsilon_{i j}^{(n)}, \mu_{p q}^{(n)}, d_{i p q}^{(n)}, \varepsilon_{i j}^{(n)}$.

Based on the linear equations and relations (2.1) и (2.2), without loss of generality, the mathematical modeling of the electromagnetoelasticity boundary value problem is presented in the paper for piezo dielectric multilayered composite, in the case of adhesive electroelastic filling occupying region $\Omega_{3}=\left\{|x|<\infty, h_{1}(x) \leq y \leq h_{2}(x),|z|<\infty\right\}$ and two adjacent piezo dielectric half-spaces (thick layer) occupying regions $\Omega_{1}=\left\{|x|<\infty,-\infty<y \leq h_{1}(x),|z|<\infty\right\}$ $\Omega_{2}=\left\{|x|<\infty, h_{2}(x) \leq y<\infty,|z|<\infty\right\}$

with rough surfaces $y=h_{1}(x)$ and $y=h_{2}(x)$ respectively. The materials of adhered electromagnetoelastic thick layers, adhesive and piezo dielectric crystals belong to the class of $6 \mathrm{~mm}$ hexagonal symmetry, physical anisotropy axis (the axis of polarization of piezoelectric crystals) coincide with the geometric axes oz and the plane oxy coincides 
with the symmetry plane of piezocrystals. The coordinate axe $0 x$ is directed along middle line of composite plane cut $y=\left[h_{2}(x)-h_{1}(x)\right] / 2$ (Fig.2).

The anti-plane deformation electroelastic equations can be written as

$G_{n} \frac{\partial^{2} w_{n}}{\partial x^{2}}+e_{n} \frac{\partial^{2} \varphi_{n}}{\partial x^{2}}+\frac{\partial \sigma_{32}^{(n)}}{\partial y}=\rho_{n} \frac{\partial^{2} w_{n}}{\partial t^{2}}, e_{n} \frac{\partial^{2} w_{n}}{\partial x^{2}}-\varepsilon_{n} \frac{\partial^{2} \varphi_{n}}{\partial x^{2}}+\frac{\partial D_{2}^{(n)}}{\partial y}=0$,

where $\sigma_{23}^{(n)}=G_{n}\left(\partial w_{n} / \partial y\right)+e_{n}\left(\partial \varphi_{n} / \partial y\right)$ are electromechanical shear stresses, $D_{2}^{(n)}=e_{n}\left(\partial w_{n} / \partial y\right)-\varepsilon_{n}\left(\partial \varphi_{n} / \partial y\right)$ are normal components of the electric displacement, $G_{n}=c_{44}^{(n)}$ are shear modulus, $\rho_{n}$ are the bulk densities, $e_{n}=e_{15}^{(n)}$ are the piezoelectric modulus, $\varepsilon_{n}=\varepsilon_{11}^{(n)}$ are coefficients of dielectric permittivity in $n=1,2,3$ layers, correspondingly.

On rough interfaces $y(x)=h_{1}(x)$ и $y(x)=h_{2}(x)$ the following electromechanical conditions of the perfect contact of mechanical and electric fields should be considered:

$\sigma_{23}^{(1)}\left[x, h_{1}(x), t\right]=\sigma_{23}^{(3)}\left[x, h_{1}(x), t\right], \sigma_{23}^{(2)}\left[x, h_{2}(x), t\right]=\sigma_{23}^{(3)}\left[x, h_{2}(x), t\right]$,

$D_{2}^{(1)}\left[x, h_{1}(x), t\right]=D_{2}^{(3)}\left[x, h_{1}(x), t\right], D_{2}^{(2)}\left[x, h_{2}(x), t\right]=D_{2}^{(3)}\left[x, h_{2}(x), t\right]$,

$\varphi_{1}\left[x, h_{1}(x), t\right]=\varphi_{3}\left[x, h_{1}(x), t\right], \varphi_{2}\left[x, h_{2}(x), t\right]=\varphi_{3}\left[x, h_{2}(x), t\right]$,

$w_{1}\left[x, h_{1}(x), t\right]=w_{3}\left[x, h_{1}(x), t\right], w_{2}\left[x, h_{2}(x), t\right]=w_{3}\left[x, h_{2}(x), t\right]$,

together with attenuation conditions

$\begin{aligned} \lim _{y \rightarrow+\infty} w_{1}(x, y, t) \rightarrow 0 & \lim _{y \rightarrow-\infty} w_{2}(x, y, t) \rightarrow 0 \\ \lim _{y \rightarrow+\infty} \varphi_{1}(x, y, t) \rightarrow 0 & \lim _{y \rightarrow-\infty} \varphi_{2}(x, y, t) \rightarrow 0 .\end{aligned}$

In specific problems, layers may contact with each other directly, without an adhesive. In this case in (2.3) the equations with index $n=3$ should be omitted and the boundary conditions (2.4)-(2.7) should be transformed into new one at middle surface/line of the two roughness $y=\left[h_{2}(x)-h_{1}(x)\right] / 2$

When the interface adheres by other electro-magneto-elastic adhesive, in an adhesive layer equations do not coincide with (2.3) and the other equations should be considered.

Below it will be shown, that the assumption of the choice of materials and adhesives interface layers does not violate the principle of generality of mathematical modeling of boundary value problem for materials with different characteristics of electromagnetoelasticity.

3. Boundary problem modelling [17]. Taking into account the fact that the value of the maximum peaks and troughs in the surface roughness is much smaller than the thickness of the effective boundary layers where the wave energy is localized, but compared with length of propagating signal

$H_{3}=\max \left|h_{3}(x)=h_{2}(x)-h_{1}(x)\right| \ll \min \left\{H_{1} ; H_{2}\right\}$

$H_{3}=\max \left|h_{3}(x)\right| \sim \lambda=2 \pi / k$

we can use a virtual model of a thin layer. Namely, for the gap of variable width between two adjacent bodies we propose the new hypotheses of thin layer presenting in the inner 
layer for the elastic displacement and the potentials of the electric and magnetic fields in the following form

$$
\begin{aligned}
& w_{3}(x, y, t)=\left[\frac{y-h_{1}(x)}{h_{2}(x)-h_{1}(x)}\right]^{m} \cdot\left[w_{2}\left(x, h_{2}(x), t\right)-w_{1}\left(x, h_{1}(x), t\right)\right]+w_{1}\left(x, h_{1}(x), t\right), \\
& \varphi_{3}(x, y, t)=\left[\frac{y-h_{1}(x)}{h_{2}(x)-h_{1}(x)}\right]^{k} \cdot\left[\varphi_{2}\left(x, h_{2}(x), t\right)-\varphi_{1}\left(x, h_{1}(x), t\right)\right]+\varphi_{1}\left(x, h_{1}(x), t\right), \\
& \psi_{3}(x, y, t)=\left[\frac{y-h_{1}(x)}{h_{2}(x)-h_{1}(x)}\right]^{s} \cdot\left[\psi_{2}\left(x, h_{2}(x), t\right)-\psi_{1}\left(x, h_{1}(x), t\right)\right]+\psi_{1}\left(x, h_{1}(x), t\right),
\end{aligned}
$$

This character of hypothetical distributions of the unknown quantities is selected primarily based on the need to compliance with the boundary conditions on the interfaces of a thin layer.

By means of (3.1) and (3.2) the two pairs of boundary conditions (2.6) and (2.7) are satisfied immediately. Naturally, under other boundary conditions, for example, when the first layer is absolutely rigid, the distribution (3.1) takes the form

$w_{3}(x, y, t)=\left[\frac{y-h_{1}(x)}{h_{2}(x)-h_{1}(x)}\right]^{m} \cdot w_{2}\left(x, h_{2}(x), t\right)$

ensuring the fulfillment of the boundary conditions with a rigid boundary $y=h_{1}(x)$

$w_{3}\left[x, h_{1}(x), t\right]=0, \quad w_{3}\left[x, h_{2}(x), t\right]=w_{2}\left[x, h_{2}(x), t\right]$

When the first layer is the perfect conductor, the distribution (3.2) becomes similar to $(3.1 *)$ type

$\varphi_{3}(x, y, t)=\left[\frac{y-h_{1}(x)}{h_{2}(x)-h_{1}(x)}\right]^{k} \cdot \varphi_{2}\left(x, h_{2}(x), t\right)$

ensuring the fulfillment of the boundary conditions with an electrically shorted boundary $y=h_{1}(x)$

$\varphi_{3}\left[x, h_{1}(x), t\right]=0, \quad \varphi_{3}\left[x, h_{2}(x), t\right]=\varphi_{2}\left[x, h_{2}(x), t\right]$

In the introduced hypotheses, the different degrees $\{m, k, s\} \in\{1 ; 2 ; 3 ; \ldots\}$ correspond to the lowest differentiation orders of required quantities in adhesive constitutive relations are taken so that in equations describing the process in the variable thickness gap the corresponding terms do not vanish. In the linear theory of the electro-magneto elasticity, where (2.1) and (2.2) are taken into account, in the distributions (3.1) - (3.3) can be taken $m=k=s=1$.

The proposed hypothesis of magneto-electro- elastic layered composite (hypothesis MELS) in the form (3.1)-(3.3) allow us to estimate physicomechanical field in a thin slit filled with an adhesive of appropriate characteristics.

In the framework of the proposed hypotheses for piezoelectric adhesive when $m=k=s=1$ the mechanical stress and electric potential in layer are constant over the thickness of the gap, but vary longitudinally along surfaces depending on the gap width.

$\xi(x) \triangleq h_{3}(x)=h_{2}(x)-h_{1}(x)$.

Introducing a new variable defining gap, the shear stress and electric displacement in the gap region can be described as 
$\sigma_{23}^{(3)}=G_{3} \frac{\partial W(x, \xi, t)}{\partial \xi}+e_{3} \frac{\partial \Phi(x, \xi, t)}{\partial \xi}, D_{2}^{(3)}=e_{3} \frac{\partial W(x, \xi, t)}{\partial \xi}-\varepsilon_{3} \frac{\partial \Phi(x, \xi, t)}{\partial \xi}$

Here $W(x, \xi, t)=w_{2}\left(x, h_{2}(x), t\right)-w_{1}\left(x, h_{1}(x), t\right)$,

$\Phi(x, \xi, t)=\varphi_{2}\left(x, h_{2}(x), t\right)-\varphi_{1}\left(x, h_{1}(x), t\right)$

are the difference shear elastic displacement and the difference electric potential in the region.

Hence, it is clear that the conditions of electromechanical field quantities finiteness (continuity condition) lead to the requirement of a limited difference of elastic displacement and electric potential at the surface irregularities. In fact, depending on the roughness of interfaces of contacting layers a longitudinally inhomogeneous electromechanical load arise at the interfaces of these layers.

On the other hand, these loads arise in a layer of sticker and satisfy to following equations

$$
\left[\tilde{G}_{3} \frac{\partial^{2}}{\partial x^{2}}-\rho_{3} \frac{\partial^{2}}{\partial t^{2}}\right] w_{3}(x, y, t)=0, \frac{\partial^{2}}{\partial x^{2}}\left[\varphi_{3}(x, y, t)-\frac{e_{3}}{\varepsilon_{3}} w_{3}(x, y, t)\right]=0
$$

From (3.5), when $\{m, k, s\} \in\{1 ; 2 ; 3 ; \ldots\}$ based on the hypotheses (3.1) and (3.2) and the last two pairs of boundary conditions (2.6) and (2.7), for the elastic displacements $w_{n}(x, y, t), \quad n=1,2$ and the electric potentials $\varphi_{n}(x, y, t), n=1,2$, we obtain the new boundary relations

$$
\begin{aligned}
& {\left[\tilde{G}_{3} \frac{\partial^{2}}{\partial x^{2}}-\rho_{3} \frac{\partial^{2}}{\partial t^{2}}\right]\left[\left(h_{2}(x)-h_{1}(x)\right) \frac{w_{2}\left(x, h_{2}(x), t\right)+w_{1}\left(x, h_{1}(x), t\right)}{2}\right]=0} \\
& \frac{\partial^{2}}{\partial x^{2}}\left[\left[\varphi_{2}\left(x, h_{2}(x), t\right)+\varphi_{1}\left(x, h_{1}(x), t\right)\right] \frac{h_{2}(x)-h_{1}(x)}{2}\right]= \\
& =\frac{e_{3}}{\varepsilon_{3}} \frac{\partial^{2}}{\partial x^{2}}\left[\left[w_{2}\left(x, h_{2}(x), t\right)+w_{1}\left(x, h_{1}(x), t\right)\right] \frac{h_{2}(x)-h_{1}(x)}{2}\right]
\end{aligned}
$$

Let us pay attention (3.5) to the nature of the dynamics of shear displacement in the adhesive layer $w_{3}(x, y, t) \simeq W_{03}(x, y) \cdot f\left[x \pm c_{\phi}(\omega) t\right], \quad c_{\phi}(\omega)=\tilde{G}_{3} / \rho_{3}$.

By integrating the equations of electrodynamics (2.3) and using MELS hypotheses (3.1),(3.2) related to linear distributions of elastic displacement and electric potential across the thickness of a thin layer of stickers, and taking into account the boundary conditions (2.4), (2.5), we obtain the generalized boundary conditions for stresses $\sigma_{23}^{(1)}(x, y, t)$

$$
\begin{aligned}
& \sigma_{23}^{(2)}(x, y, t) \text { and electric displacements } D_{2}^{(1)}(x, y, t) \quad D_{2}^{(2)}(x, y, t) \\
& \left.\tilde{G}_{2} \frac{\partial w_{2}(x, y, t)}{\partial y}\right|_{y=h_{2}(x)}-\left.\tilde{G}_{1} \frac{\partial w_{1}(x, y, t)}{\partial y}\right|_{y=h_{1}(x)}= \\
& =\left[\rho_{3} \frac{\partial^{2}}{\partial t^{2}}-\tilde{G}_{3} \frac{\partial^{2}}{\partial x^{2}}\right]\left[\left[w_{2}\left(x, h_{2}(x), t\right)+\frac{\alpha_{13}^{2}}{\alpha_{23}^{2}} w_{1}\left(x, h_{1}(x), t\right)\right] \frac{h_{2}(x)-h_{1}(x)}{2}\right]
\end{aligned}
$$


$\left.\varepsilon_{1} \frac{\partial \phi_{1}(x, y, t)}{\partial y}\right|_{y=h_{1}(x)}-\left.\varepsilon_{2} \frac{\partial \phi_{2}(x, y, t)}{\partial y}\right|_{y=h_{2}(x)}=$

$\varepsilon_{3} \frac{\partial^{2}}{\partial x^{2}}\left[\frac{h_{2}(x)-h_{1}(x)}{2} \cdot\left[\phi_{1}\left(x, h_{1}(x), t\right)+\phi_{2}\left(x, h_{2}(x), t\right)\right]\right]$

In (3.8), (3.9 $\alpha_{n 3}^{2}=1+\left(e_{3} / e_{n}\right)\left(G_{n} / G_{3}\right) \cdot \chi_{n}^{2}$ are interconnection coupling coefficients in a three-layer piezo dielectric composite $\chi_{n}^{2}=e_{n}^{2} /\left(\varepsilon_{n} \cdot G_{n}\right), \quad n=1,2 . \quad$, are electromechanical piezoelectric coupling coefficients of adjacent half-spaces, $\phi_{n}(x, y, t)=\varphi_{n}(x, y, t)-\left(e_{n} / \varepsilon_{n}\right) w_{n}(x, y, t), \quad n=1,2$. is the well-known notation the of electroelastic potential for piezo dielectrics of $6 \mathrm{~mm}$ class of hexagonal symmetry. Thus the problem of the propagation of shortwave -electroelastic plane signal propagation in multilayer piezo dielectric composite, by means of the MELS hypotheses is reduced to the solution of the electro-elasticity quasi-static, anti-plane equations

$G_{n} \frac{\partial^{2} w_{n}}{\partial x^{2}}+G_{n} \frac{\partial^{2} w_{n}}{\partial y^{2}}+e_{n} \frac{\partial^{2} \varphi_{n}}{\partial x^{2}}+e_{n} \frac{\partial^{2} \varphi_{n}}{\partial y^{2}}=\rho_{n} \frac{\partial^{2} w_{n}}{\partial t^{2}}$

$e_{n} \frac{\partial^{2} w_{n}}{\partial x^{2}}+e_{n} \frac{\partial^{2} w_{n}}{\partial y^{2}}-\varepsilon_{n} \frac{\partial^{2} \varphi_{n}}{\partial x^{2}}-\varepsilon_{n} \frac{\partial^{2} \varphi_{n}}{\partial y^{2}}=0, \quad$ при $\quad n=1,2$.

with attenuation conditions (2.8) and generalized boundary conditions (3.6)-(3.9) of full electromagnetic contact which can be presented in a rather simplified form

$$
\begin{aligned}
& {\left.\left[G_{1} \frac{\partial w_{1}(x, y, t)}{\partial y}+e_{1} \frac{\partial \varphi_{1}(x, y, t)}{\partial y}\right]\right|_{y=h_{1}(x)}-} \\
& -\left[G_{2} \frac{\partial w_{2}(x, y, t)}{\partial y}+\left.e_{2} \frac{\partial \varphi_{2}(x, y, t)}{\partial y}\right|_{y=h_{2}(x)}=0\right. \\
& {\left.\left[e_{1} \frac{\partial w_{1}(x, y, t)}{\partial y}-\varepsilon_{1} \frac{\partial \varphi_{1}(x, y, t)}{\partial y}\right]\right|_{y=h_{1}(x)}-} \\
& -\left.\left[e_{2} \frac{\partial w_{2}(x, y, t)}{\partial y}-\varepsilon_{2} \frac{\partial \varphi_{2}(x, y, t)}{\partial y}\right]\right|_{y=h_{2}(x)}=0 \\
& {\left[\tilde{G}_{3} \frac{\partial^{2}}{\partial x^{2}}-\rho_{3} \frac{\partial^{2}}{\partial t^{2}}\right]\left[\left(h_{2}(x)-h_{1}(x)\right) \frac{w_{2}\left(x, h_{2}(x), t\right)+w_{1}\left(x, h_{1}(x), t\right)}{2}\right]=0} \\
& \frac{\partial^{2}}{\partial x^{2}}\left[\left[\varphi_{2}\left(x, h_{2}(x), t\right)+\varphi_{1}\left(x, h_{1}(x), t\right)\right] \frac{h_{2}(x)-h_{1}(x)}{2}\right]= \\
& =\frac{e_{3}}{\varepsilon_{3}} \frac{\partial^{2}}{\partial x^{2}}\left[\left[w_{2}\left(x, h_{2}(x), t\right)+w_{1}\left(x, h_{1}(x), t\right)\right] \frac{h_{2}(x)-h_{1}(x)}{2}\right]
\end{aligned}
$$


From these boundary conditions, it follows that non-smoothness boundary conditions $h_{n}(x), n=1 ; 2, \quad \xi \triangleq h_{3}(x)=h_{2}(x)-h_{1}(x)$ play an important role transforming homogeneous boundary conditions into longitudinally conditions. The dynamics of adhesive longitudinally inhomogeneous thin layer is conditioned by these boundary conditions and may result both in a synchronism and in an internal resonance between waves in the adjacent semi-spaces.

4. Solution of the problem.

It is known that solutions of anti plane electroelastic problem attenuated along the depths of adjacent semi-spaces in the case of shear electroelastic signal propagation $F(x, y, t)=A(y) \cdot \exp \{i(k x-\omega t)\}$

in adjacent semi-spaces can be presented as $w_{n}(x, y, t)=A_{n} \exp \left((-1)^{n} \alpha_{n} k y\right) \cdot \exp \{i(k x-\omega t)\}$

$\varphi_{n}(x, y, t)=\left\{B_{n} \exp \left((-1)^{n} k y\right)+\frac{e_{n}}{\varepsilon_{n}} A_{n} \exp \left((-1)^{n} \alpha_{n} k y\right)\right\} \cdot \exp \{i(k x-\omega t)\}$

where $\quad \alpha_{n}^{2}=1-\left(\omega^{2} \rho_{n}^{2}\right) /\left(k^{2} \tilde{G}_{n}^{2}\right)$ are characteristic wave numbers $n=1 ; 2$; $k=(2 \pi) / \lambda$ is wave number, $\lambda=2 \pi / k$ is the length, $\omega$-the frequency of the wave signal. Based on (4.1), from boundary conditions (3.11)-(3.14), we can obtain a transcendence characteristic equation describing the wave process in the composite $\left\|\begin{array}{ll}f_{11} & f_{12} \\ f_{31} & f_{32}\end{array}\right\| \cdot\left\|\begin{array}{ll}f_{23} & f_{24} \\ f_{43} & f_{44}\end{array}\right\|-\left\|\begin{array}{ll}f_{31} & f_{32} \\ f_{41} & f_{42}\end{array}\right\| \cdot\left\|\begin{array}{ll}f_{13} & f_{14} \\ f_{23} & f_{24}\end{array}\right\|=0$,

where coefficients $f_{i j}\left(h_{n}(x), k(\omega)\right)$ depend both on the relative physical and mechanical constants of materials: $b_{i} / b_{j}$, where $b \in\{G, \rho, \mathrm{e}, \varepsilon\}, \quad i, \mathrm{j} \in\{1,2,3\}$, $d_{n 3}=\left(e_{n} / \varepsilon_{n}-e_{3} / \varepsilon_{3}\right), n=1 ; 2$, and from functions of non-smooth interfaces of adjacent semi-spaces функций, phase function $k(\omega)$,

$$
\begin{aligned}
& f_{12}\left(h_{n}(x), k(\omega)\right)=\tilde{G}_{2} \alpha_{2} e^{\alpha_{2} k h_{2}(x)} \\
& f_{13}\left(h_{n}(x), k(\omega)\right)=e_{1} e^{-k h_{1}(x)}, \quad f_{14}\left(h_{n}(x), k(\omega)\right)=e_{2} e^{k h_{2}(x)} \\
& f_{23}\left(h_{n}(x), k(\omega)\right)=\varepsilon_{1} e^{-k h_{1}(x)}, \quad f_{24}\left(h_{n}(x), k(\omega)\right)=\varepsilon_{2} e^{k h_{2}(x)} \\
& f_{31}\left(h_{n}(x), k(\omega)\right)=\left\{\begin{array}{l}
{\left[\Delta h_{, x x}(x)+2 i k \Delta h_{, x}(x)-k^{2} \alpha_{3}^{2} \Delta h(x)\right]} \\
-\left[2 \Delta h_{, x}(x)+2 i k \Delta h(x)\right] \cdot \alpha_{1} k h_{1, x}(x) \\
+\Delta h(x)\left[\alpha_{1}^{2} k^{2} h_{1, x}^{2}(x)-\alpha_{1} k h_{1, x x}(x)\right]
\end{array}\right\} \cdot e^{-\alpha_{1} k h_{1}(x)}
\end{aligned}
$$




$$
\begin{aligned}
& f_{32}\left(h_{n}(x), k(\omega)\right)=\left\{\begin{array}{l}
{\left[\Delta h_{, x x}(x)+2 i k \Delta h_{, x}(x)-k^{2} \alpha_{3}^{2} \Delta h(x)\right]} \\
+\left[2 \Delta h_{, x}(x)+2 i k \Delta h(x)\right] \cdot \alpha_{2} k h_{2, x}(x) \\
+\Delta h(x)\left[\alpha_{2}^{2} k^{2} h_{2, x}^{2}(x)+\alpha_{2} k h_{2, x x}(x)\right]
\end{array}\right\} \cdot e^{\alpha_{2} k h_{2}(x)} \\
& f_{41}\left(h_{n}(x), k(\omega)\right)=d_{13}\left\{\begin{array}{l}
{\left[\Delta h_{, x x}(x)+2 i k \Delta h_{, x}(x)-k^{2} \Delta h(x)\right]} \\
-\left[2 \Delta h_{, x}(x)+2 i k \Delta h(x)\right] \cdot \alpha_{1} k h_{1, x}(x) \\
+\Delta h(x)\left[\alpha_{1}^{2} k^{2} h_{1, x}^{2}(x)-\alpha_{1} k h_{1, x x}(x)\right]
\end{array}\right\} \cdot e^{-\alpha_{1} k h_{1}(x)} \\
& f_{42}\left(h_{n}(x), k(\omega)\right)=d_{23}\left\{\begin{array}{l}
{\left[\Delta h_{, x x}(x)+2 i k \Delta h_{, x}(x)-k^{2} \Delta h(x)\right]} \\
+\left[2 \Delta h_{, x}(x)+2 i k \Delta h(x)\right] \cdot \alpha_{2} k h_{2, x}(x) \\
+\Delta h(x)\left[\alpha_{2}^{2} k^{2} h_{2, x}^{2}(x)+\alpha_{2} k h_{2, x x}(x)\right]
\end{array}\right\} \cdot e^{\alpha_{2} k h_{2}(x)} \\
& f_{43}\left(h_{n}(x), k(\omega)\right)=\left\{\begin{array}{l}
{\left[\Delta h_{, x x}(x)+2 i k \Delta h_{, x}(x)-k^{2} \Delta h(x)\right]} \\
-\left[2 \Delta h_{, x}(x)+2 i k \Delta h(x)\right] \cdot k h_{1, x}(x) \\
+\Delta h(x)\left[k^{2} h_{1, x}^{2}(x)-k h_{1, x x}(x)\right]
\end{array}\right\} \cdot e^{-k h_{1}(x)} \\
& f_{44}\left(h_{n}(x), k(\omega)\right)=\left\{\begin{array}{l}
{\left[\Delta h_{, x x}(x)+2 i k \Delta h_{, x}(x)-k^{2} \Delta h(x)\right]} \\
+\left[2 \Delta h_{, x}(x)+2 i k \Delta h(x)\right] \cdot k h_{2, x}(x) \\
+\Delta h(x)\left[k^{2} h_{2, x}^{2}(x)+k h_{2, x x}(x)\right]
\end{array}\right\} \cdot e^{k h_{2}(x)}
\end{aligned}
$$

It is obvious, that this transcendental dispersion equation can be investigated numerically with the given functions of non-smooth semi-spaces. On the other hand it is clear that the longitudinal heterogeneity conditioned by boundary roughness, leads to wave signal scattering resulting for complex wave namber $k=k_{1}+i k_{2}$. Then in the solutions (4.1), as well as in expressions (3.1) and (3.2) the amplitude and velocity of propagation of the signal prior electroelastic may also vary along the wave signal propagation direction $O X$.

\section{Specific example.}

Let us consider the propagation of an anti plane shear plane wave signal $w(x, y, t)=\left[A_{1} e^{\alpha k y}+A_{2} e^{-\alpha k y}\right] \cdot \mathrm{e}^{i(k x-\omega t)}$ in a non piezo active waveguide $\left\{-\infty<x<+\infty, h_{-}(x) \leq y \leq h_{+}(x),-\infty<z<+\infty\right\}$ with surface roughness $y=h_{ \pm}(x)$,

Introducing virtual heterogeneous subsurface layers, with middle planes $y= \pm h_{0}$, corresponding to rough surfaces and taking into account that waveguide surfaces are adjacent with vacuum, we obtain $\sigma_{32}^{( \pm)}\left[x, h_{ \pm}(x), t\right]=0$ и $\varphi_{ \pm}\left[x, h_{ \pm}(x), t\right]=\varphi_{0 \pm}\left[x, h_{ \pm}(x), t\right]$.

Based on MELS hypotheses from (3.1) and (3.2) introducing virtual distribution functions in surface layers from (3.1) и (3.2) 
$w_{ \pm}(x, y, t)=\frac{y}{ \pm h_{0}} w\left(x, \pm h_{0}, t\right)$

$\varphi_{ \pm}(x, y, t)=\frac{y-h_{ \pm}(x)}{ \pm h_{0}-h_{ \pm}(x)}\left[\varphi\left(x, h_{0}, t\right)-\varphi_{0 \pm}\left(x, h_{ \pm}(x), t\right)\right]+\varphi_{0 \pm}\left(x, h_{ \pm}(x), t\right)$,

we obtain generalized boundary conditions which are taking into account roughness irregularities in the middle planes $y= \pm h_{0}$

$\left.G \frac{\partial w(x, y, t)}{\partial y}\right|_{y= \pm h_{0}}=\left.\frac{\left(h_{ \pm}^{2}(x)-h_{0}^{2}\right)}{ \pm 2 h_{0}}\left[G \frac{\partial^{2} w(x, y, t)}{\partial x^{2}}-\rho \frac{\partial^{2} w(x, y, t)}{\partial t^{2}}\right]\right|_{y= \pm h_{0}}$

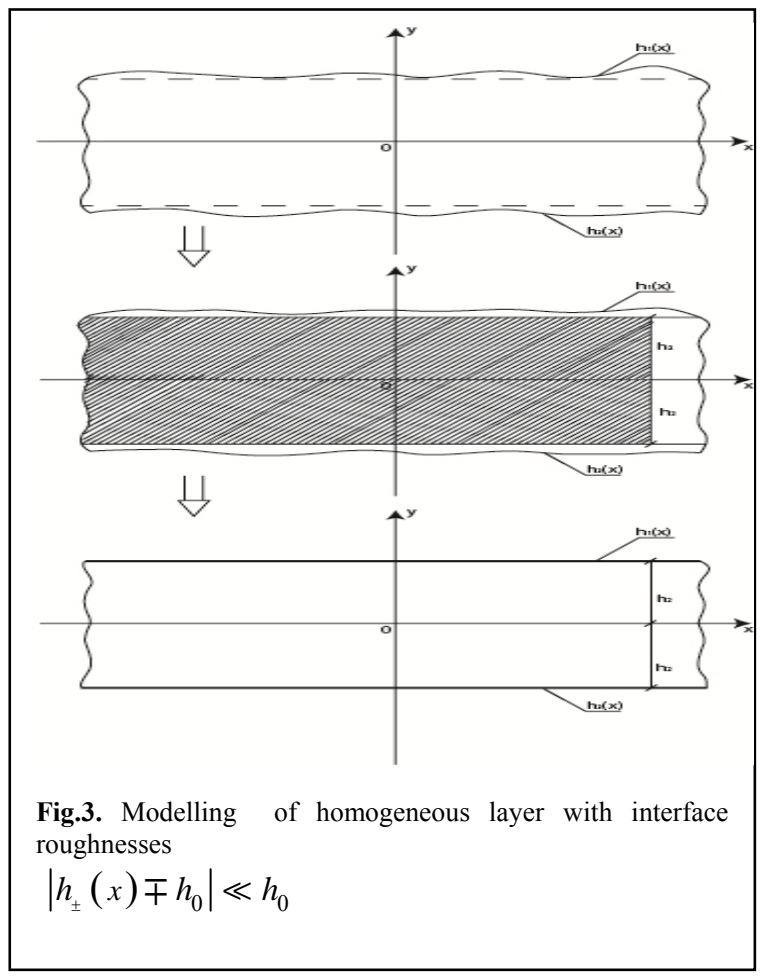

As seen, the roughness on the surfaces of the waveguide leads to the dynamic loads on the surfaces, which may generate waves of new harmonics or internal resonance in subsurface zone, as well as prohibit the propagation of waves of a certain frequency to form silent bands in the waveguide.

In fact, the roughness of the surface forms a longitudinal inhomogeneity layer, where the heterogeneity transforms a prewave signal to generalized shear waves

$w(x, y, t)=\left[A_{1}(x, t) \cdot e^{\alpha k y}+\right.$

$\left.+A_{2}(x, t) \cdot e^{-\alpha k y}\right] \cdot e^{i(k x-\omega t)}$

where wave number $k(\omega)=2 \pi / \lambda, \quad$ or $\quad$ vibration frequency $\omega(k)$ are complex ones.

A characteristic formation number $p(\omega, x)=(2 \pi \cdot \alpha(\omega, x)) / \lambda$ depending also on the frequency of the propagating wave signal depends on the roughness zones $x \in\left[x_{i} ; x_{i+1}\right]$ at the surface. The function $p(\omega, x)$ is determined from the transcendental dispersion equation

$F(p, x)=e^{-4 p}-\frac{\left[1+\frac{p}{2}\left(d_{-}^{2}(x)-1\right)\right] \cdot\left[1+\frac{p}{2}\left(d_{+}^{2}(x)-1\right)\right]}{\left[1-\frac{p}{2}\left(d_{-}^{2}(x)-1\right)\right] \cdot\left[1-\frac{p}{2}\left(d_{+}^{2}(x)-1\right)\right]}=0$

where the following notations are used $d_{ \pm}^{2}(x)=\Delta h_{ \pm}^{2}(x) / h_{0}^{2} \quad \Delta h_{ \pm}(x)=\left|h_{ \pm}(x) \mp h_{0}\right|$. 
Analytical analysis shows, that in the case of high-frequency signal propagation with speed $V_{0 \phi}=C_{0}=\sqrt{G / \rho}$ the availability of sagging irregularities (pits) on the surface of waveguide $d_{ \pm}^{2}(x)-1 \leq 0$ also leads to the appearance of new dispersion wave modes propagating with the speeds $V_{1 \phi}(\omega, x)=C_{0} \sqrt{1-\left[p_{1}^{*}(\omega, x)\right]^{2} /(k h)^{2}}$, $V_{2 \phi}(\omega, x)=C_{0} \sqrt{1-\left[p_{2}^{*}(\omega, x)\right]^{2} /(k h)^{2}}$

The formation functions $p_{1}^{*}(\omega, x), p_{2}^{*}(\omega, x) \quad 0 \leq p_{1}^{*}(\omega, x)<2 /\left[1-d_{-}^{2}(x)\right]$ $p_{2}^{*}(\omega, x)>2 /\left[1-d_{+}^{2}(x)\right]$ indicate the existence of a short and localized shear waves near the $y=-h, y=h$ surfaces, respectively.

In this case, for high-frequency signals there is a stopband region $2 /\left[1-d_{-}^{2}(x)\right] \leq p(\omega, x) \leq 2 /\left[1-d_{+}^{2}(x)\right]$, where the shear waves of certain frequencies cannot propagate.

Similarly, if we have a layer with tightening borders, i.e. $\left|h_{ \pm}(x)\right| \geq h$ and hence $d_{ \pm}^{2}(x)-1 \geq 0$ at both surfaces of the layer, then in this case the shear wave can propagate with the speed $V=C_{0}^{2}=G / \rho$ only.

And finally, if at some interval on one surface of the waveguide there is a pit, we suppose that $d_{-}^{2}(x)-1 \leq 0$, if on at opposite surface there is a bulge we suppose that $d_{+}^{2}(x)-1 \geq 0$, then in the case of propagation of high-frequency signal propagation with a speed $V_{0 \phi}=C_{0}=\sqrt{G / \rho}$ a new type of wave dispersion mode occurs, the nature of which is determined by the ratio of the "pit" depth and the "bulge" height:

a) If $h_{+}^{2}(x)<h_{-}^{2}(x)-4 h_{-}(x) \cdot \Delta h_{-}(x)+2 \cdot \Delta h_{-}^{2}(x)$, then the wave dispersion mode occurs localized at $y=-h$ surface and propogate with speed $V_{3 \phi}(\omega, x)=C_{0} \sqrt{1-\left[p_{3}^{*}(\omega, x)\right]^{2} /(k h)^{2}}$, where $0 \leq p_{3}^{*}(\omega, x)<2 /\left[1-d_{-}^{2}(x)\right]$,

б) if $h_{+}^{2}(x)>h_{-}^{2}(x)-4 h_{-}(x) \cdot \Delta h_{-}(x)+2 \cdot \Delta h_{-}^{2}(x)$, then the wave dispersion mode of other type occurs localized at $y=-h$ surface also and traveling with speed $V_{4 \phi}(\omega, x)=C_{0} \sqrt{1-\left[p_{4}^{*}(\omega, x)\right]^{2} /(k h)^{2}}$, where $p_{4}^{*}(\omega, x)>2 /\left[1-d_{-}^{2}(x)\right]$,

Let us as a rough surface layer take the same equidistant surface $h_{ \pm}(x)= \pm h_{0}\left(1+\gamma_{0} \sin (k \delta x)\right)$, where $2 h_{0}$ is the estimated thickness of the layer, $\gamma_{0}$ is the maximum height of the roughness profile, and $\delta$ is the average pitch of surface irregularities profile. Then, according to (5.3) we have $\Delta h_{ \pm}(x)=h_{0} \gamma_{0} \sin (k \delta x), d_{ \pm}^{2}(x)=\gamma_{0}^{2} \sin ^{2}(k \delta x)$ and therefore in this case the dispersion equation (5.3) separates into two simplified ones

$$
F_{1}(p, x)=e^{-2 p}-\frac{2+p\left[\gamma_{0}^{2} \sin ^{2}(k \delta x)-1\right]}{2-p\left[\gamma_{0}^{2} \sin ^{2}(k \delta x)-1\right]}=0
$$




$$
F_{2}(p, x)=e^{-2 p}+\frac{2+p\left[\gamma_{0}^{2} \sin ^{2}(k \delta x)-1\right]}{2-p\left[\gamma_{0}^{2} \sin ^{2}(k \delta x)-1\right]}=0
$$

From (5.3.1) and (5.3.2) follows, that for a perfectly smooth surface layer $\delta \equiv 0$ or $\gamma_{0} \equiv 0$, only the primary signal propagates with the phase velocity $V_{0 \phi}=C_{0}=\sqrt{G / \rho}$. As always $\gamma_{0}^{2} \sin ^{2}(k \delta x)-1<0$, and for formative number we have $0<p(\omega, x)=(2 \pi \cdot \alpha(\omega, x)) / \lambda<\infty$, then the equations (5.3.1) and (5.3.2) besides the primary signal also allow new wave mode with the forming number close to $p=2 /\left[1-\gamma_{0}^{2} \sin ^{2}(k \delta x)\right]$. At each change $(n / 2) \cdot(\lambda / \delta) \leq x \leq((n+1) / 2) \cdot(\lambda / \delta)$ the formative number varies between $2 \leq p(\omega, x) \leq 2 /\left(1-\gamma_{0}^{2}\right)$, making one complete cycle.

Depending on the ratio of the wavelength to the average spacing irregularities, the periodic metric segment expands or narrows.

\section{Conclusion.}

The hypothesis of magneto-electro-mechanical field for rough border zone of magnetoelectro elastic layered composites is formulated (hypothesis MELS), which allows to identify the nature of the dynamic effects of boundary roughness on the propagation of a wave magneto-electric elastic signal.

The dispersion relation for a three-layer piezo dielectric composite is obtained when the rough surfaces are in full contact.

On the illustrative task, the propagation of wave signals is considered in a single layer waveguide with a rough surface free of electromechanical surfaces it is shown that the roughness leads to the solution of the wave propagation problem in the waveguide with perfectly smooth boundaries on which there are additional dynamic electromechanical loads depending on the interaction of a propagating electroelastic signal with rough boundaries. The possibility of the appearance of new modes of shear wave caused by the surface roughness of the elastic waveguide is studied analytically.

\section{References:}

1. Biryukov S.V., Gulyaev Y.V., Krylov V., Plessky V. Surface acoustic waves in inhomogeneous media. // Springer Series on Wave Phenomena, Vol. 20, 1995, 388.

2. Brekhovskikh L. Waves in Layered Media 2e. //Applied mathematics and mechanics, Vol. 16, Elsevier Science, 2012, 520.

3. Daniel Royer. Eugene Dieulesaint Elastic Waves in Solids I: Free and Guided Propagation. //Springer Science \& Business Media, 2000, 374.

4. Lobkist 0.I., Chimenti D.E. Elastic guided waves in plates with rough surfaces. //Appl. Phys. Lett. Vol. 69, 3486-3497 (1996).

5. Berman D.H. Computations of rough surface reflection coefficients in a waveguide. // J. Acoust., Soc. Am. Vol. 96, 2834-2843 (1996).

6. Schmidt H. and Kuperman W.A. Spectral representations of rough interface reverberation in stratified ocean waveguides.// J. Acoust. Soc. Am. Vol. 97(4), 21992209 (1995).

7. Shchegrov A.V. Propagation of surface acoustic waves across the randomly rough surface of an anisotropic elastic medium. //J. Appl. Phys. Vol. 78, 1565 (1995). 
8. Flannery CM, von Kiedrowski H. Effects of surface roughness on surface acoustic wave propagation in semiconductor materials. //Ultrasonics. 2002 Vol. 40 (Issues 18): 83-87.

9. SinghS.S. Love Wave at a Layer Medium Bounded by Irregular Boundary Surfaces. //Journal of Vibration and Control, 2010; Vol.16. 1177.

10. Mal A.K., P.-C. Xu Elastic Waves in Layered Media with Interface Features. //NorthHolland Series in Applied Mathematics and Mechanics, Vol. 35, 1989, p. 67-73.

11. Mikhail V. Golub and Chuanzeng Zhang. In-plane time-harmonic elastic wave motion and resonance phenomena in a layered phononic crystal with periodic cracks. //J. Acoust. Soc. Am. Vol.137, Issues 1, 2015, 238.

12. Carbone G., Scaraggi M., Tartaglino U. Adhesive contact of rough surfaces: comparison between numerical calculations and analytical theories., Eur Phys. J. E Soft Matter., 2009, Vol.30(Issues 1), 65-74.

13. Feng J., Zikun W., Tiejun W. The Bleustein-Gulyaev (B-G) wave in a piezoelectric layered half-space // Int. J. Eng Sci. 2001. Vol. 39. P. 1271-1285.

14. Svetovoy V.B., Palasantzas G. Influence of surface roughness on dispersion forces, Adv Colloid Interface Sci., 2015; 216, C.1-19.

15. Амбарцумян С.А., Багдасарян Г.Е. Белубекян М.В. Магнитоупругость тонких пластин и оболочек. М.: Наука, 1977. 324c.

16. Аветисян А.С. К задаче распространения сдвиговых волн в пьезоэлектрической среде. //Изв. АН Арм.ССР. Механика. 1985. Т.38. №1. С.12-19.

17. Avetisyan A.S. The boundary problem modelling of rough surfaces continuous media with coupled physical and mechanical fields. //Reports of NAS of Armenia, 2015, vol.115, №2, pp.91-104.

\section{Acknowledgment}

This research was supported by State Committee of Science of Armenia Grant No. SCS 13$2 \mathrm{C} 005$.

\section{Сведения об авторе:}

Аветисян Ара Сергеевич - Чл.-корр. НАН РА, доктор физ.-мат.наук, Институт механики НАН Армении.

Адрес: 0019, Ереван, пр. Маршала Баграмяна, 24/2, тел.: (+37493)00-44-55.

E-mail: ara.serg.avetisyan@,gmail.com 